\title{
BMJ Open Risk factors for pain and functional impairment in people with knee and hip osteoarthritis: a systematic review and meta-analysis
}

\author{
Sandeep Sandhar, ${ }^{1}$ Toby O Smith (D , ${ }^{2}$ Kavanbir Toor, ${ }^{1}$ Franklyn Howe, ${ }^{3}$ \\ Nidhi Sofat (D) ${ }^{1}$
}

To cite: Sandhar S, Smith T0, Toor K, et al. Risk factors for pain and functional impairment in people with knee and hip osteoarthritis: a systematic review and meta-analysis. BMJ Open 2020;10:e038720. doi:10.1136/ bmjopen-2020-038720

- Prepublication history and additional material for this paper are available online. To view these files, please visit the journal online (http://dx.doi. org/10.1136/bmjopen-2020038720).

Received 23 March 2020 Revised 03 June 2020 Accepted 23 June 2020

Check for updates

(C) Author(s) (or their employer(s)) 2020. Re-use permitted under CC BY. Published by BMJ.

1 Institute for Infection and Immunity, University of London St George's, London, UK ${ }^{2}$ Nuffield Department of Orthopaedics and Musculoskeletal Sciences, University of Oxford, Oxford, UK ${ }^{3}$ Molecular and Clinical Sciences Research Institute, University of London St George's, London, UK

Correspondence to

Professor Nidhi Sofat;

nsofat@sgul.ac.uk

\section{ABSTRACT}

Objective To identify risk factors for pain and functional deterioration in people with knee and hip osteoarthritis $(\mathrm{OA})$ to form the basis of a future 'stratification tool' for $\mathrm{OA}$ development or progression.

Design Systematic review and meta-analysis.

Methods An electronic search of the literature databases, Medline, Embase, CINAHL, and Web of Science (1990February 2020), was conducted. Studies that identified risk factors for pain and functional deterioration to knee and hip OA were included. Where data and study heterogeneity permitted, meta-analyses presenting mean difference (MD) and ORs with corresponding 95\% Cls were undertaken. Where this was not possible, a narrative analysis was undertaken. The Downs \& Black tool assessed methodological quality of selected studies before data extraction. Pooled analysis outcomes were assessed and reported using the Grading of Reccomendation, Assessment, Development and Evaluation (GRADE) approach.

Results 82 studies (41810 participants) were included. On meta-analysis: there was moderate quality evidence that knee $O A$ pain was associated with factors including: Kellgren and Lawrence $\geq 2$ (MD: $2.04,95 \% \mathrm{Cl} 1.48$ to $2.81 ; p<0.01$ ), increasing age (MD: $1.46,95 \% \mathrm{Cl} 0.26$ to 2.66; $\mathrm{p}=0.02$ ) and whole-organ MRI scoring method (WORMS) knee effusion score $\geq 1$ (OR: $1.35,95 \% \mathrm{Cl} 0.99$ to $1.83 ; p=0.05)$. On narrative analysis: knee $O A$ pain was associated with factors including WORMS meniscal damage $\geq 1$ (OR: 1.83). Predictors of joint pain in hip $0 A$ were large acetabular bone marrow lesions (BML; OR: 5.23), chronic widespread pain (OR: 5.02) and large hip BMLs (OR: 4.43).

Conclusions Our study identified risk factors for clinical pain in $\mathrm{OA}$ by imaging measures that can assist in predicting and stratifying people with knee/hip OA. A 'stratification tool' combining verified risk factors that we have identified would allow selective stratification based on pain and structural outcomes in $\mathrm{OA}$.

PROSPERO registration number CRD42018117643.

\section{INTRODUCTION}

It has been reported that over 30.8 million US adults suffer from osteoarthritis (OA). ${ }^{1}$ Between 1990 and 2010, the years lived with
Strengths and limitations of this study

- This study has been reported in accordance with the Preferred Reporting Items for Systematic Reviews and Meta-Analyses reporting checklist.

- Analyses have been undertaken respecting potential sources of known statistical heterogeneity.

- Searches included both published and unpublished sources of literature to reduce the risk of omitting potentially eligible data.

- There was a paucity of available data to permit meta-analyses of risk factors for pain and functional impairment.

- The variability in methods of assessing risk and reporting of frequency of risk characteristics limited analyses.

disability worldwide caused by $\mathrm{OA}$ increased from 10.5 million to 17.1 million, an increase of $62.9 \% .^{2}$ Current OA treatment lacks any disease-modifying treatments with a predominance to manage symptoms rather than modify underlying disease. ${ }^{3}$ The clinical symptoms of OA can be assessed using several questionnaires, the most common of which is the Western Ontario and Mcmaster Universities Osteoarthritis Index (WOMAC). ${ }^{4-6}$ Although pain is recognised as an important outcome measure in $\mathrm{OA}$, it is not clear what the optimal assessment tools are in OA and how they relate to other risk factors.

OA has various subtypes and since current therapies cannot prevent OA progression, early detection and stratification of those at risk may enable effective presymptomatic interventions. ${ }^{78}$ Several methods are used to define, diagnose and measure OA progression, including imaging techniques (eg, plain radiography, CT and MRI). Plain radiography provides high contrast and high-resolution images for cortical and trabecular bone, but not for non-ossified structures (eg, synovial 
fluid). ${ }^{9}$ The most recognised radiographic measure classifying OA severity is Kellgren and Lawrence (KL) grading which assesses osteophytes, joint space narrowing (JSN), sclerosis and bone deformity. ${ }^{10}{ }^{11}$ However, it has been argued that MRI may be more suitable for imaging arthritic joints, providing a whole organ image of the joint. ${ }^{12}$ Whole-organ MRI scoring method (WORMS) is used in MRI for OA assessing damage, providing a detailed analysis of the joint.

Recently, Outcome Measures in RheumatologyOsteoarthritis Research Society International (OMERACT-OARSI) have published a core domain set for clinical trials in hip and/or knee OA. ${ }^{13}$ Six domains were assessed as mandatory in the assessment of OA, including pain, physical function, quality of life, patient's global assessment of the target joint and adverse events including mortality and/or joint structure, depending on the intervention tested. However, there remains a need to identify risk factors for pain and structural damage in $\mathrm{OA}$ so that potential interventions can be studied in a timely manner. The purpose of this systematic review was therefore to identify risk factors for pain, worsening function and structural damage that can predict knee/hip OA development and progression. By identifying risk factors for OA pain and structural damage, tools for stratifying specific disease groups could be developed in the future.

\section{METHODS}

This systematic review has been reported in accordance with the Preferred Reporting Items for Systematic Reviews and Meta-Analyses reporting guidelines.

\section{Search strategy}

A systematic search of the literature was undertaken from 1 January 1990 to 1 February 2020 using electronic databases: Medline (Ovid), Embase (Ovid), Medline, Web of Science and CINAHL (EBSCO). An example of the Embase search strategy of included search terms and Boolean operators is presented in online supplementary file 1. Unpublished literature databases including Clinicaltrials.gov, the WHO International Registry of Clinical Trials and OpenGrey were also searched.

\section{Study identification}

Studies were eligible for inclusion if they were a full-text article that satisfied all of the following:

1. One hundred or more participants analysed in the study (to increase power for comparisons).

2. Convincing definition of OA using American College of Rheumatology criteria, ${ }^{14}$ based on symptoms of sustained pain and stiffness in the affected joint, radiographic changes including osteophytes, cartilage loss, bone cysts/sclerosis and JSN, with normal inflammatory markers.

3. Abstract/title that must refer to pain and/or structure in relation to $\mathrm{OA}$ as a primary disease.

4. Knee or hip OA.
5. Pain and/or function scores.

6. Joint imaged.

7. Minimum 6-month follow-up of pain/function outcome measures.

Non-English studies, letters, conference articles and reviews were excluded.

The titles and abstracts were reviewed by one reviewer (SS). The full text for each paper was assessed for eligibility by one reviewer (SS) and double-checked by a second (TOS). Any disagreements were addressed through discussion and adjudicated by a third reviewer (NS or FH). All studies that satisfied the criteria were included in the review.

\section{Quality assessment}

To assess the risk of bias and the power of the methodology, the Downs \& Black (D\&B) tool was applied. ${ }^{15}$ These tools assessed the following aspects of each study: reporting quality, external validity, internal validity-bias, selection bias and power. The modified D\&B tool was used. Accordingly, the 27-item randomised controlled trial (RCT) version was used for RCTs while the 18-item non-RCT version was used for non-RCT designs (online supplementary file 2). Both 18-item and 27-item tools have been demonstrated to be valid and reliable tools to assess RCT and non-RCT papers. ${ }^{14}$ Critical appraisal was performed by one reviewer (SS) and verified by a second (KT). Any disagreements were dealt with by discussion and adjudicated through a third reviewer (TOS). In previous literature, D\&B score ranges were given corresponding quality: excellent (scored 26-28); good (scored 20-25); fair (scored 15-19); and poor (scored <14). ${ }^{14}$ Item 4 on the non-RCT and item 5 from the RCT tool are scored two points; hence, the total scores equate to 19 and 28 points, respectively. The D\&B tool was used to exclude poor quality studies with a score $15 / 28$ or lower in RCTs and 10/19 or lower in non-RCTs.

\section{Data extraction}

Data were extracted including: subject demographic data, study design, pain and function outcome measures, imaging used, OA severity scores, change in pain and function outcomes and change in OA severity scores. After all relevant data had been extracted, authors of these papers were approached to try and attain individual patient data related to baseline and change in pain, function and structural scores for each study. No data were received from authors to inform this analysis.

\section{Outcomes}

The primary outcome was to determine the development of pain and functional impairment for those with knee and hip OA. The secondary outcome was to determine which factors are associated with structural changes in knee and hip OA.

\section{Data analysis}

All data were assessed for study heterogeneity through scrutiny of the data extraction tables. These identified 
that there was minimum study-based heterogeneity based on: population, study design and interventions-exposure variabilities for given outcomes. Where there was study heterogeneity, a narrative analysis was undertaken. In this instance, the ORs of all predictor variables were tabulated with a range of OR presented. Where there was sufficient data to pool (two or more studies with data available to analyse) and study homogeneity evident, a pooled metaanalysis was deemed appropriate. As interpreted by the Cochrane Collaboration, ${ }^{16}$ when $\mathrm{I}^{2}$ was $50 \%$ or greater representing high-statistical heterogeneity, a randomeffect model meta-analysis was undertaken. When $\mathrm{I}^{2}$ was less than this figure, a fixed effects model approach was adopted. Continuous outcomes were assessed using mean difference (MD) scores of measures for developing severe OA, whereas dichotomous variables were assessed through OR data. All data were presented with $95 \%$ CIs and forest plots.

Due to the presentation of the data, there were minimal data to permit meta-analyses. Where there were insufficient data to pool the analysis (data only available from one study), a narrative analysis was undertaken to assess risk factors for the development of increased pain and functional impairment. Planned subgroup analyses included determine whether there was a difference in risk factors based on: (1) anatomical regions (ie, difference between hip OA and knee OA); (2) geographical region. Analyses were undertaken on STATA V.14.0 (Stata Corp) with forest plots constructed using RevMan Review Manager (RevMan; Computer program; V.5.3. Copenhagen: The Nordic Cochrane Centre, The Cochrane Collaboration, 2014.)

\section{Patient and public involvement}

The research team acknowledges the assistance of both the OA tech network and Engineering and Physical Sciences Research Council. The authors also acknowledge receiving assistance from a meeting that enabled a consensus to be met on the eligibility criteria to be used, and this meeting consisted of the following people: Angela Kedgley, Abiola Harrison, Alan Boyde, Alan Silman, Amara Ezeonyeji, Caroline Hing, Cathy Holt, Debbie Rolfe, Enrica Papi, Freija Ter Heegde, Jingsong Wang, John Garcia, Mark Elliott, Mary Sheppard, Natasha Kapella, Richard Rendle, Shafaq Sikandar, Sherif Hosny, Soraia Silva, Soraya Koushesh, Susanna Cooper and Thomas Barrick. No writing assistance was used.

\section{RESULTS}

\section{Search strategy}

The results of the search strategy are presented in figure 1. In total, 11010 citations were identified. Of these, 141 papers were deemed potentially eligible and screened at full-text level. Of these, 82 met the selected criteria and were included. ${ }^{17-98}$

\section{Characteristics of included studies}

A summary of the included studies is presented as table 1. This consisted of 31 non-RCTs (27 observational cohort studies/four case-control studies) and 51 RCTs.

In total, 45767 knees were included in the analysis. This consisted of 13870 men and 23497 women; 4 studies did not report the gender of their cohorts. ${ }^{17-20}$ Thirty-six studies were undertaken in the USA; 30 were undertaken in Europe; 9 were conducted in Australasia and 7 in Asia. Mean age of the cohorts was 61.7 years (SD: 7.56); 36 studies did not report age. ${ }^{171-54}$ Mean follow-up period was 35.4 months (SD: 33.6). The most common measures of pain were WOMAC pain $(\mathrm{n}=55 ; 50 \%)$ and Visual Analogue Scale (VAS) Pain $(n=21 ; 19 \%)$. The most frequently used measures of function were WOMAC function $(\mathrm{n}=52 ; 44 \%)$, physical tests $(\mathrm{n}=16 ; 14 \%)$ and SF-36 $(\mathrm{n}=10 ; 9 \%)$.

\section{Methodological quality assessment}

The methodological quality of the evidence was moderate (online supplementary file 2;. Based on the results of the D\&B non-RCT tool (31 studies; online supplementary file 2), recurrent strengths of the evidence were clear description of the participants recruited (29 studies; $94 \%)$, the representative nature that participants were to the population (31 studies; $100 \%$ ), and variability in data presented for the main outcomes (31 studies; 100\%). Furthermore, the main outcome measures were deemed reliable and valid in all studies (31 studies; 100\%) with 89\% (27 studies; 87\%) studies adopting appropriate statistical analyses for their datasets. Recurrent limitations were not clearly reporting the main findings (20 studies; $65 \%$ ), issues regarding the representation of the cohort from the wider public (18 studies; $58 \%$ ) and only 6 studies (19\%) basing their sample sizes on an a prior power calculation.

The results from the D\&B RCT checklist (51 studies; online supplementary file 3) similarly reported findings with strength of the evidence around clear reporting of the cohort characteristics (49 studies; 96\%) and interventions (50 studies; 98\%), adoption of reliable/valid outcome measures (51 studies; 100\%) and reported high compliance to study processes (37 studies; $73 \%$ ). Recurrent weaknesses included recruiting cohorts which may not have been reflective of the wider population (19 studies; 37\%), in clinic settings which may not have represented typical clinical practice (21 studies; $41 \%$ ) and poorly adjusting for potential confounders in analyses (26 studies; $51 \%$ ).

\section{Knee OA}

Narrative review

Findings from the narrative analysis found the following were predictors for worsening joint pain: KL3 or 4 in women (OR: 11.3; 95\% CI 6.2 to 20.4), a WORMS lateral meniscal cyst (MC) score of 1 (OR: $4.3 ; 95 \%$ CI 1.2 to 15.4), presence of chronic widespread pain (CWP; OR: 3.2 ; $95 \%$ CI 1.9 to 5.3 ), increase of $\geq 2$ in WORMS BML 

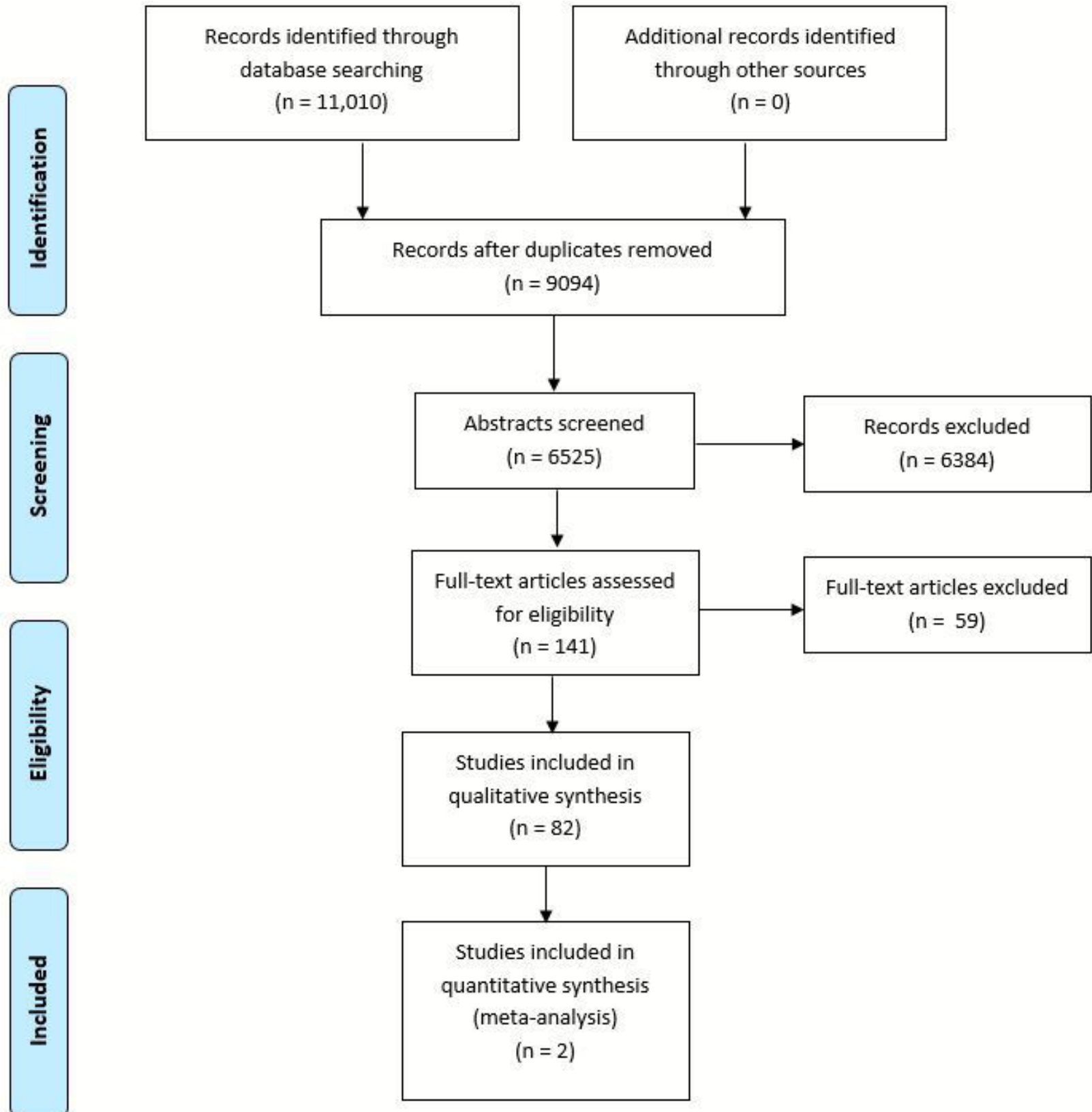

Figure 1 Preferred Reporting Items for Systematic Reviews and Meta-Analyses flow chart.

score after 15 months (OR: 3.2; 95\% CI 1.5 to 6.8), meniscal maceration (OR: 2.8; $95 \%$ CI 1.8 to 4.4 ) or damage $\geq 2$ in WORMS (OR: $1.8 ; 95 \%$ CI 0.9 to 3.6 ). We also found that the following were the highest predictors of worsening function in people with knee $\mathrm{OA}$ : $\mathrm{KL}$ of $<3$ (OR: 3.3; 95\% CI 0.7 to 15.9 ), modified KL 3a (OR: 1.7 ; 95\% CI 0.7 to 3.8 ), modified KL 4a (OR: 1.5 ; 95\% CI 0.7 to 3.0 ), presence of osteophytes (OR: $1.3 ; 95 \%$ CI 0.7 to 2.4), female gender (OR: 1.8 (95\% CI 1.1 to 3.0) to OR: 2.1 (95\% CI 1.2 to 3.5 )), ethnicity (OR: $1.03 ; 95 \%$ CI 0.59 to 1.83 ) and synovitis $\geq 1$ (OR: 1.3 ; $95 \%$ CI 0.8 to 1.9 ).

\section{Meta-analysis}

Two studies were identified where data could be evaluated for OA risk factors by meta-analysis. ${ }^{4167}$ Three variables significantly associated with the development of knee OA. As illustrated in table 2 and figure 2A-D, age (MD: $1.46,95 \%$ CI 0.26 to $2.66 ; \mathrm{p}=0.02 ; \mathrm{n}=823$ ), KL of $\geq 2$ (MD: $2.04,95 \%$ CI 1.48 to $2.81 ; \mathrm{p}<0.01 ; \mathrm{n}=823$ ) and knee effusion score $\geq 1$ (OR: 1.35 , 95\% CI 0.99 to 1.83 ; $\mathrm{p}=0.05 ; \mathrm{n}=823)$ were all associated with the development of knee OA based on moderate quality evidence. The variables of gender and BMI were not shown to be significantly associated with the knee OA development (table 2).

Due to the limited availability of data, it was not possible to conduct the planned subgroup analyses to determine whether there was a difference in risk factors based on anatomical or geographical regions. 


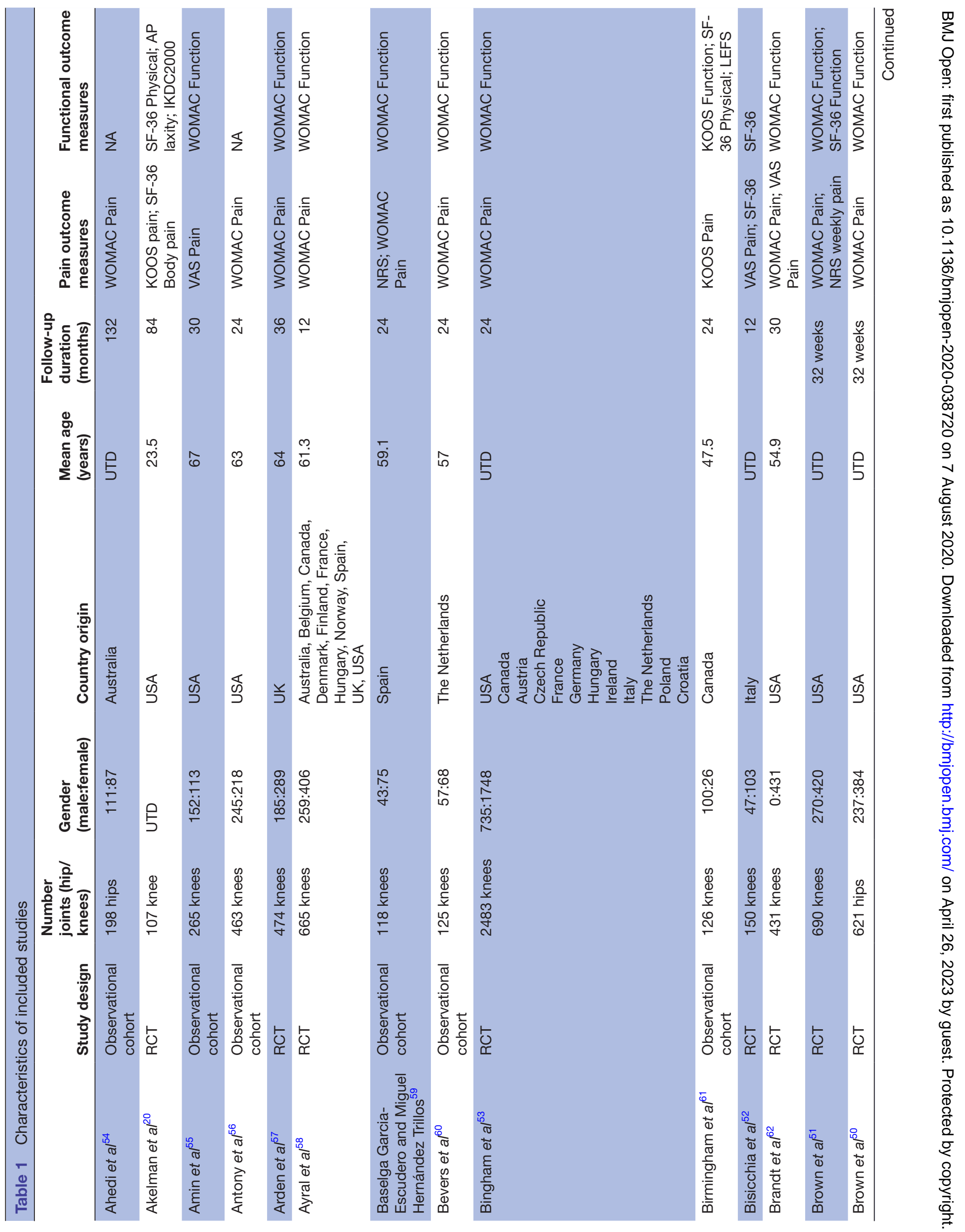




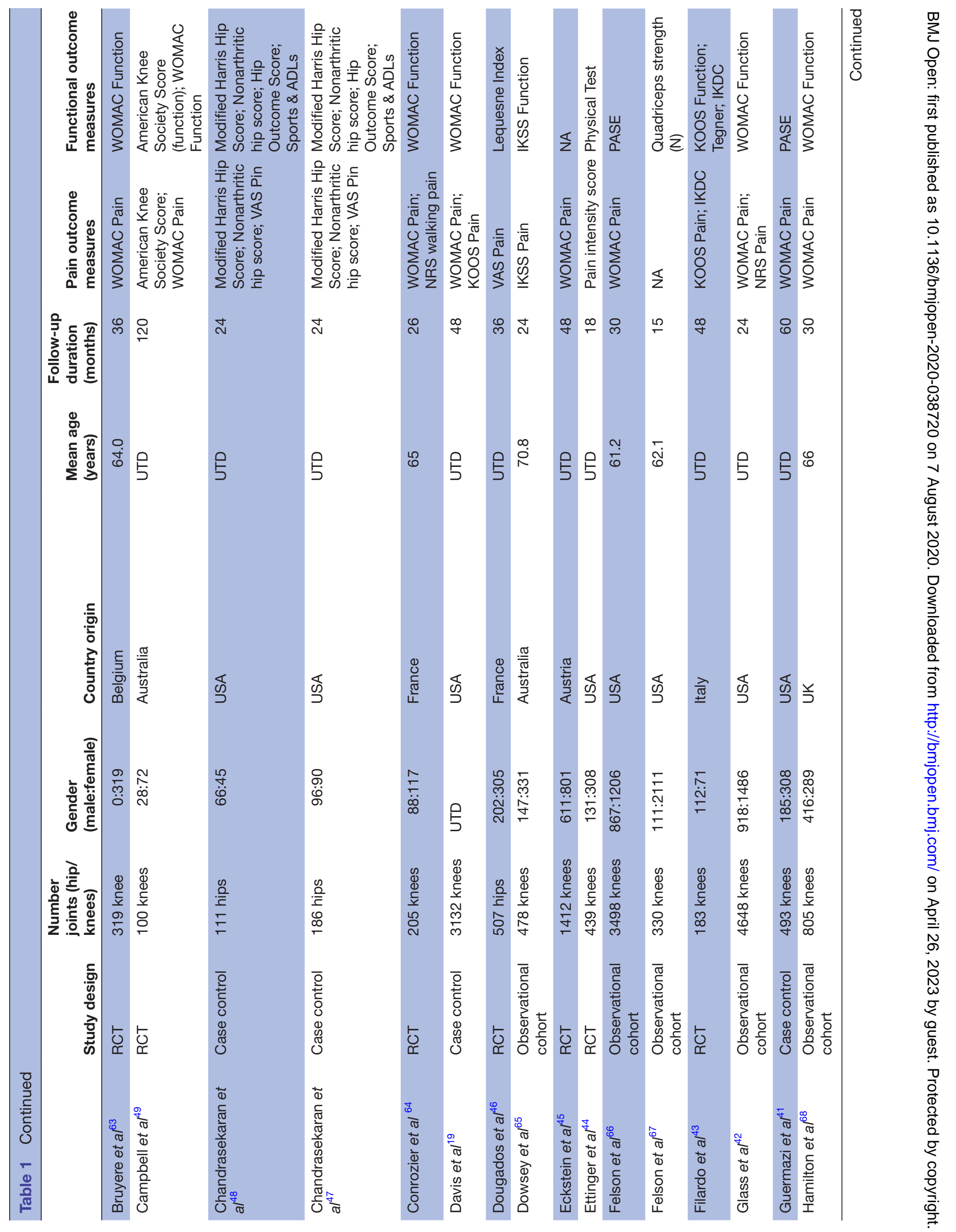




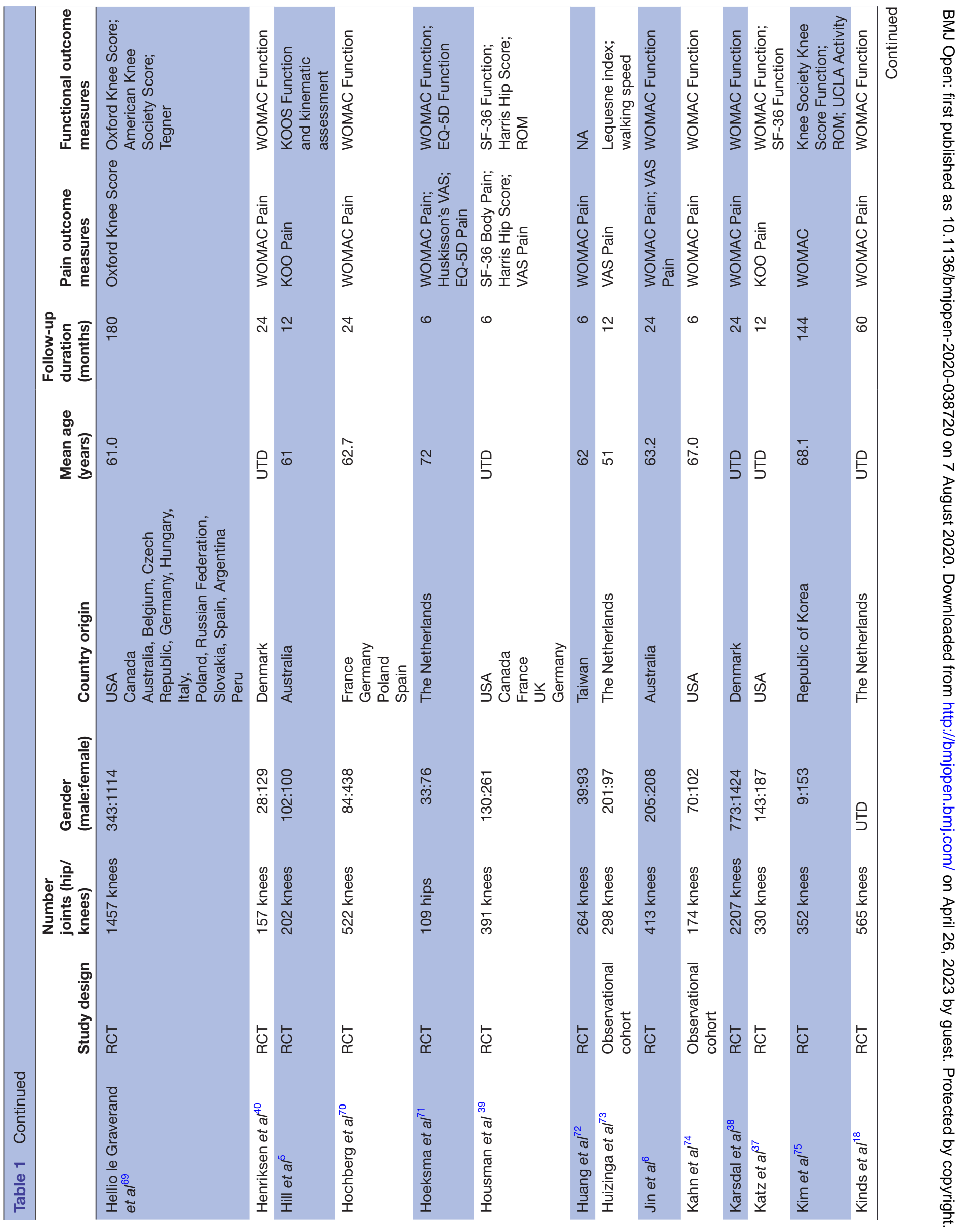




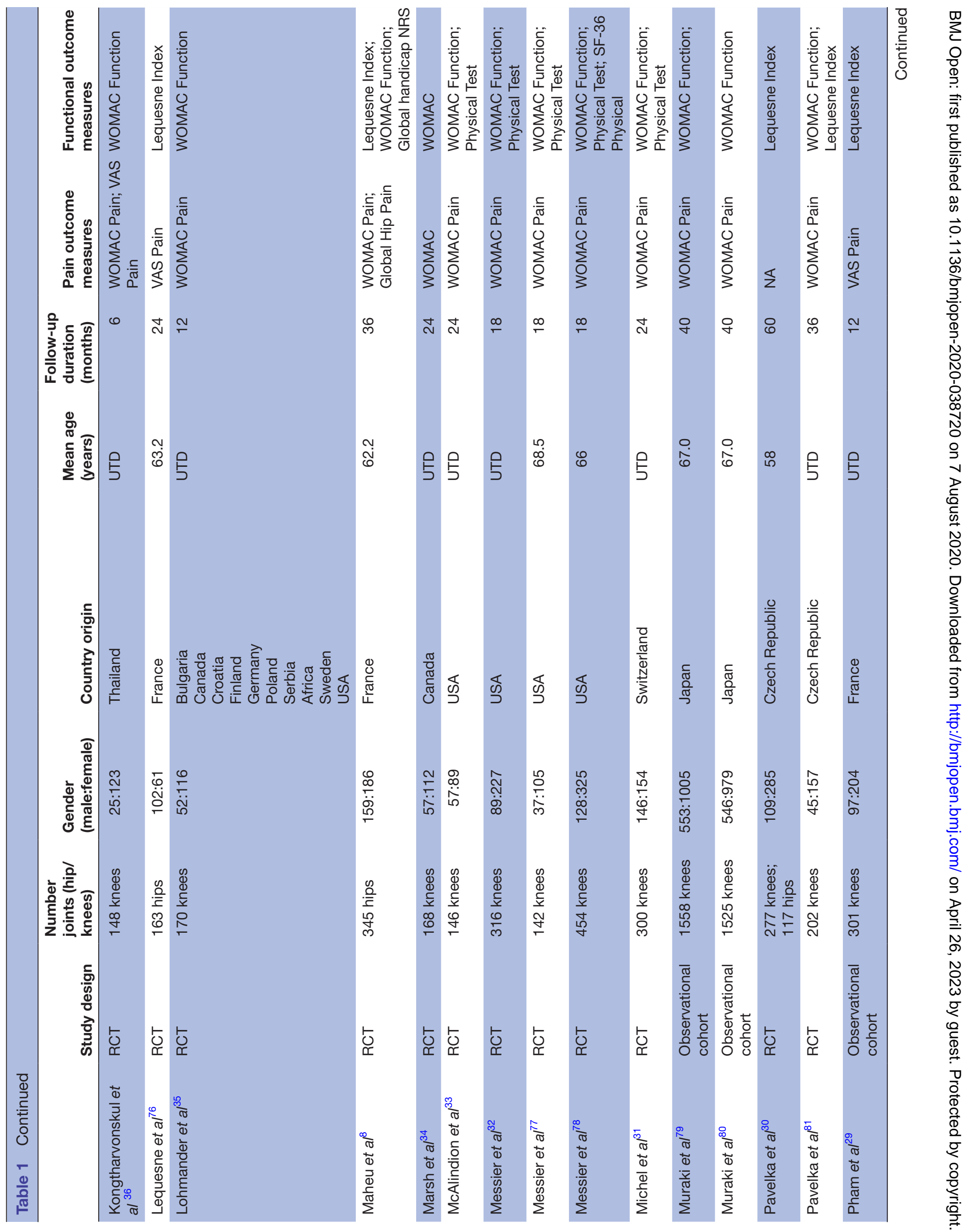




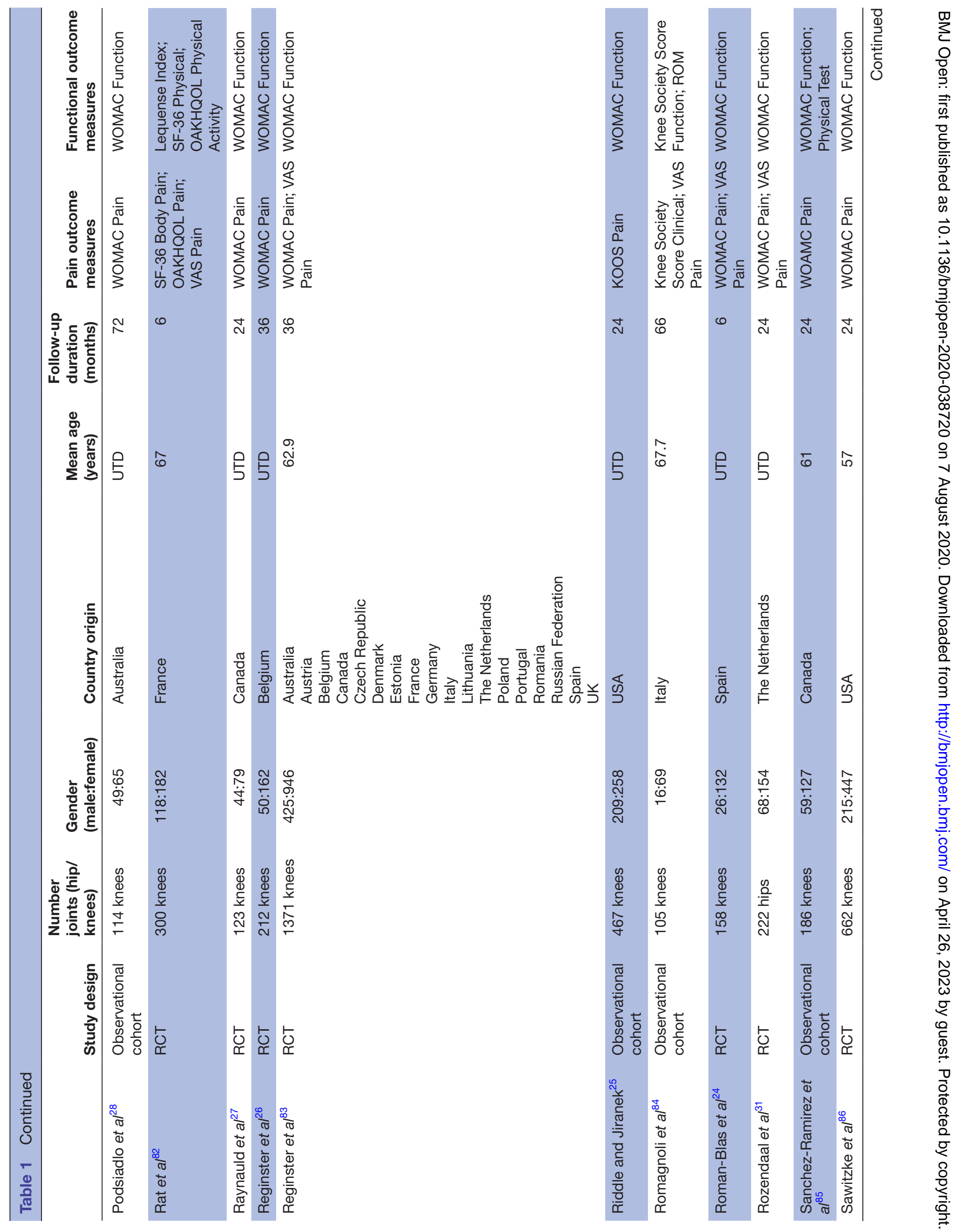




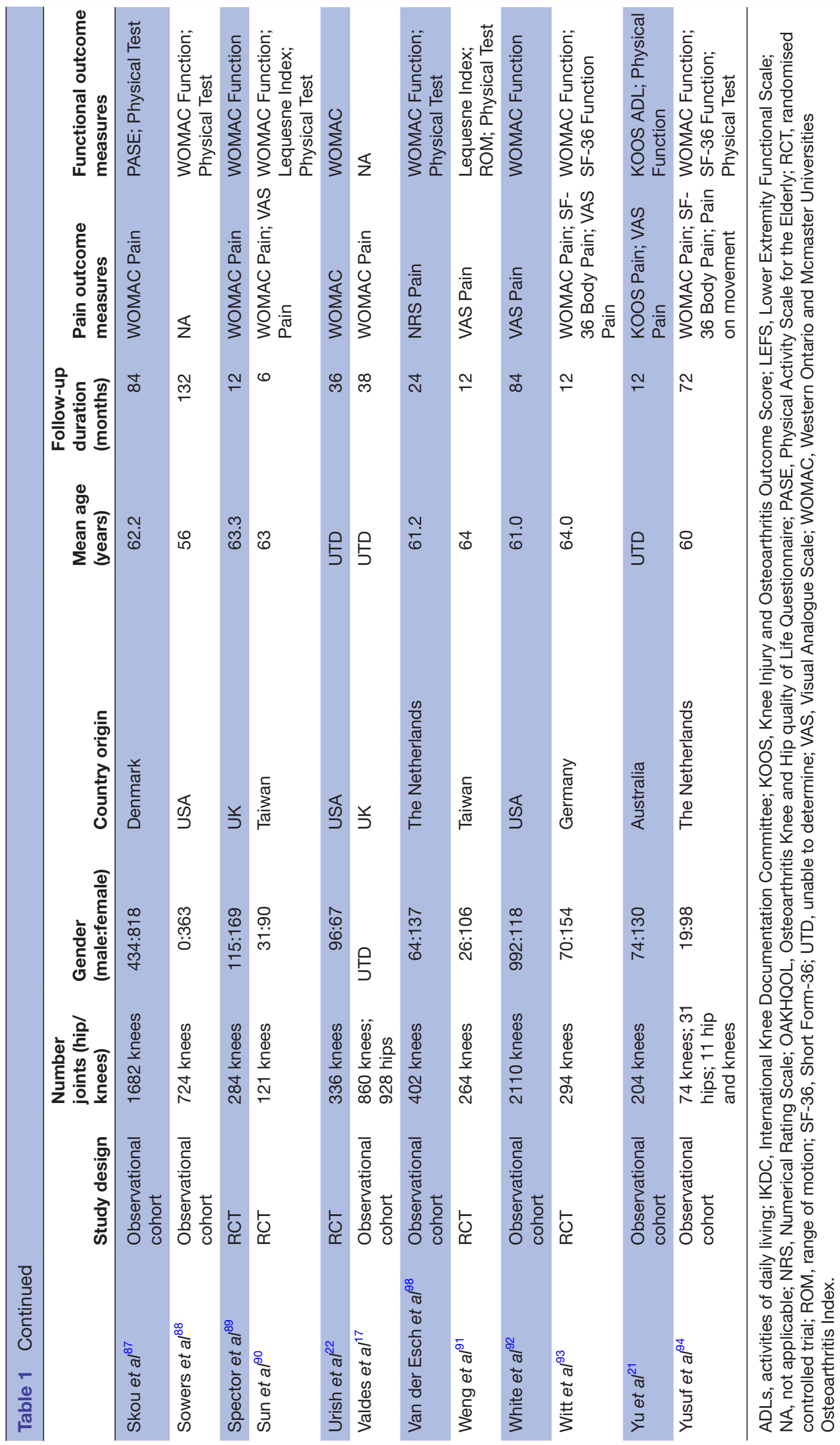


Table 2 Meta-analysis results: exhibit knee osteoarthritis

\begin{tabular}{lccccc} 
Variable & N & Effect estimate & P value & Statistical heterogeneity $\mathbf{( I}^{\mathbf{2}}$ \%) & GRADE assessment \\
\hline Gender & 823 & $0.91(0.48 \text { to } 1.72)^{*}$ & 0.78 & 87 & Low-quality evidence $\dagger$ \\
Age & 823 & $1.46(0.26$ to 2.66$)$ & 0.02 & 0 & Moderate-quality evidence $\neq$ \\
KL $\geq 2$ & 823 & $2.04(1.48$ to 2.81$)$ & $<0.01$ & 35 & Moderate-quality evidence \\
Knee effusion score $\geq 1$ & 823 & $1.35(0.99$ to 1.83$)$ & 0.05 & 0 & Moderate-quality evidence \\
BMl & 823 & $-0.08(-0.75$ to 0.58$)$ & 0.81 & 0 & Moderate-quality evidence
\end{tabular}

*Random effects model analysis.

TGRADE- outcomes downgraded one level due to risk of bias, two level due to imprecision and inconsistency.

†GRADE-outcomes downgraded one level due to risk of bias.

BMI, body mass index; I2, inconsistency squared; KL, Kellgren Lawrence Scale; N, number of participants in analysis; NE, not estimable.

\section{Hip OA}

Narrative analysis

This was based on low-quality evidence. There was no association between the development of hip BML and BMI or age. Predictors for worsening joint pain for people with hip OA included a large acetabular BML
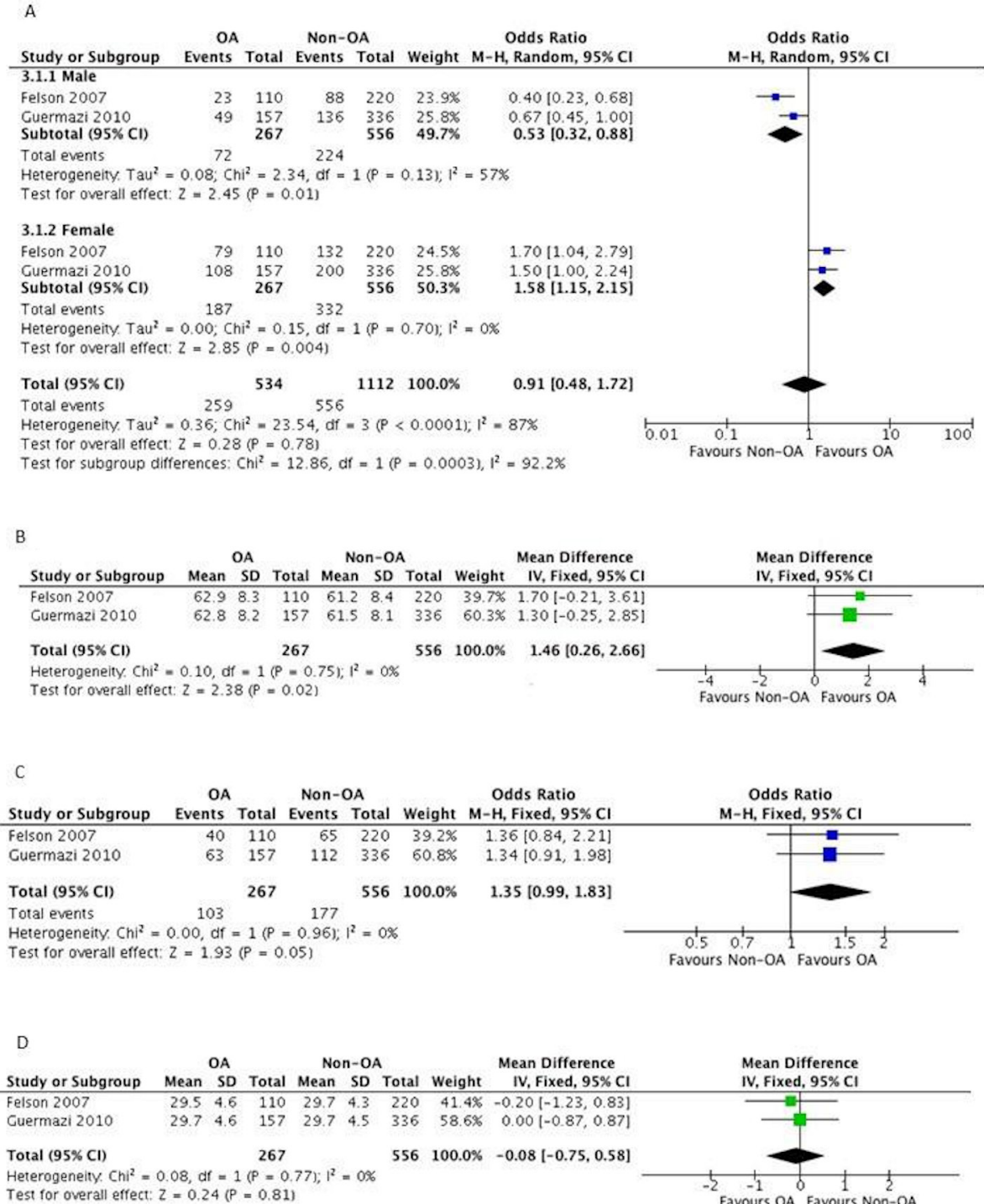

Figure 2 (A) Forest plot to present the association between gender and presentation of knee osteoarthritis (OA). (B) Forest plot to present the association between age and presentation of knee OA. (C) Forest plot to present the association between knee effusion score greater or equal to 1 and presentation of knee OA. (D) Forest plot to present the association between body mass index and presentation of knee OA. 
(OR: 5.2; 95\% CI 1.2 to 22.9), a large femoral head BML (OR: $4.4 ; 95 \%$ CI 1.4 to 19.7 ) with any large hip BML (OR: 4.4; 95\% CI 1.5 to 13.2), CWP (OR: 5.0; 95\% CI 2.8 to 9.1 ) and depression (OR: 1.9 ; $95 \%$ CI 1.2 to 2.9 ). Baseline knee pain score (MD:-1.4; $95 \% \mathrm{CI}-1.6$ to -1.2 ) and baseline hip pain score (MD:-0.7; 95\% CI -1.0 to -0.5 ) were significantly associated with the development of hip BMLs and pain.

\section{Meta-analysis}

There were insufficient data to permit meta-analysis for the hip OA dataset.

\section{DISCUSSION}

Our systematic review and meta-analysis identified risk factors for knee and hip OA pain and structural damage based on evaluation of 82 studies. For the knee, increasing pain in knee $\mathrm{OA}$ was associated with $\mathrm{KL}$ grade 3 or 4 in women, WORMS lateral MC, presence of CWP, increase of $\geq 2$ in WORMS BML score after 15 months and meniscal maceration. In addition, $\mathrm{KL}<3, \mathrm{KL} 3 \mathrm{a}$, KL 4a, osteophyte presence and female gender were associated with worsening function in people with knee OA. On meta-analysis, age, radiological features (KL score of 2 or more) and knee effusion were associated with development and/or progression of knee OA.

Our meta-analysis identified risk factors that are appreciated only when results were pooled together. These were namely WORMS-defined knee effusion score $\geq 1$. To our knowledge, this is currently the largest and most up to date systematic review of its kind, reviewing 82 primary studies in 41810 participants. Nonetheless, some risk factors from our meta-analysis have been recognised previously. For example, Silverwood et al reported previous injuries are associated to developing knee OA, supporting the present analysis. ${ }^{95}$ Kingsbury $e t$ al identified age and KL grade as predictive factors for developing knee OA, supporting the present findings. ${ }^{96}$ The metaanalyses provided both novel and supporting findings for risk factors associated with developing and progressing knee OA. A machine learning study assessed risk factors associated with pain and radiological progression in knee OA found that BMLs, osteophytes, medial meniscal extrusion, female gender and urine CTX-II contributed to progression. ${ }^{97}$ Nelson et al's work is supported by other studies. ${ }^{95} 96$ Therefore, the findings of our analysis support previous findings.

After plain radiography, MRI was the most used modality with WORMS as the most common scoring reported for MRI. The MRI Osteoarthritis Knee Score (MOAKS) ${ }^{99}$ expanded on WORMS by scoring entire subregions for BMLs rather than each BML, further division of cartilage regions and refined the features assessed in meniscal morphology. Due to this progression from WORMS, having no MOAKS studies included in our final selection was surprising. This could be due to the eligibility criteria being too restrictive. A future systematic review and meta-analysis focusing on the imaging aspect of evaluating OA will be important. In hip OA, the evaluation of BML size and location is essential in predicting pain progression and these can be assessed effectively using MRI. We recommend that all MRI studies for hip OA evaluate BML size and location.

Gait analysis is considered a risk factor for pain/function and was therefore included as a target outcome measure. However, few studies included gait analysis measures, which could not be included in the analysis, perhaps due to the minimum sample size $(n=100)$ being too restrictive.

There were several limitations within our study. First, despite identifying novel risk factors for exhibiting knee OA, a small dataset was pooled together for the meta-analysis (two studies) compared with Silverwood et al (34 studies) ${ }^{93}$ This was particularly apparent for hip OA where only 12 studies assessed this popula-

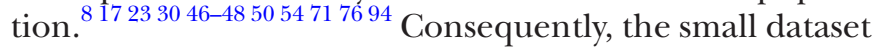
influenced the GRADE assessment that determined the evidence as low to moderate, restricting the strength of the associations of risk factors with OA development and progression. Further work may impact our confidence in the estimated effect, for both studies recruiting participants with hip and knee OA. Second, the eligibility criteria may have been too restrictive, resulting in limited papers including gait analysis or MOAKS. Wet biomarkers were not included in our analyses. Finally, the inability to pool data was partly attributed to variability in methods to report data. Standardising data collection and reporting are important in conducting meta-analyses. We believe the following should be undertaken to improve data pooling in future work: ensuring group comparisons in studies are selected from the same population (people with confirmed OA) to improve internal validity, observational studies should conduct a power analysis to determine sample sizes and all studies should include absolute frequency of events data rather than summary ORs. Such considerations will improve future meta-analyses to identify OA risk factors.

To conclude, our work helps to develop steps towards building a stratification tool for risk factors for knee OA pain and structural damage development. We also highlight the need for collection of core datasets based on defined domains, which has recently also been highlighted by the OMERACT-OARSI core domain set for knee and hip OA. ${ }^{13}$ Collection of future datasets based on standardised core outcomes will assist in more robust identification of risk factors for large joint $\mathrm{OA}$.

\section{Twitter Toby 0 Smith @tobyosmith}

Contributors Conception and design; drafting of the article; critical revision of the article; final approval of the article: NS, FH, TOS and SS. Analysis and interpretation of the data; collection and assembly of data: TOS, SS and KT. Provision of study materials or patients: N/A. Statistical expertise: TOS. Obtaining of funding; administrative, technical, or logistic support: NS, TOS and FH.

Funding This study was funded by the Engineering and Physical Sciences Research Council under the reference code 'EP/N027264/1' and The Wellcome Trust ISSF award to NS (Grant number 204809/Z/16/Z). 
Competing interests None declared.

Patient consent for publication Not required.

Provenance and peer review Not commissioned; externally peer reviewed.

Data availability statement All data relevant to the study are included in the article or uploaded as supplementary information.

Open access This is an open access article distributed in accordance with the Creative Commons Attribution 4.0 Unported (CC BY 4.0) license, which permits others to copy, redistribute, remix, transform and build upon this work for any purpose, provided the original work is properly cited, a link to the licence is given, and indication of whether changes were made. See: https://creativecommons.org/ licenses/by/4.0/.

\section{ORCID iDs}

Toby 0 Smith http://orcid.org/0000-0003-1673-2954

Nidhi Sofat http://orcid.org/0000-0002-6963-6475

\section{REFERENCES}

1 Cisternas MG, Murphy L, Sacks JJ, et al. Alternative methods for defining osteoarthritis and the impact on estimating prevalence in a US population-based survey. Arthritis Care Res 2016;68:574-80.

2 Cross M, Smith E, Hoy D, et al. The global burden of hip and knee osteoarthritis: estimates from the global burden of disease 2010 study. Ann Rheum Dis 2014;73:1323-30.

3 Wu Y, Goh EL, Wang D, et al. Novel treatments for osteoarthritis: an update. Open Access Rheumatol 2018;10:135-40.

4 Bellamy N, Buchanan WW, Goldsmith $\mathrm{CH}$, et al. Validation study of WOMAC: a health status instrument for measuring clinically important patient relevant outcomes to antirheumatic drug therapy in patients with osteoarthritis of the hip or knee. J Rheumatol 1988;15:1833-40.

5 Kraus VB, Blanco FJ, Englund M, et al. Call for standardized definitions of osteoarthritis and risk stratification for clinical trials and clinical use. Osteoarthritis Cartilage 2015;23:1233-41.

6 Jin X, Jones G, Cicuttini F, et al. Effect of vitamin D supplementation on tibial cartilage volume and knee pain among patients with symptomatic knee osteoarthritis: a randomized clinical trial. JAMA 2016;315:1005-13.

7 Hill CL, March LM, Aitken D, et al. Fish oil in knee osteoarthritis: a randomised clinical trial of low dose versus high dose. Ann Rheum Dis 2016;75:23-9.

8 Maheu E, Cadet C, Marty M, et al. Randomised, controlled trial of avocado-soybean unsaponifiable (Piascledine) effect on structure modification in hip osteoarthritis: the ERADIAS study. Ann Rheum Dis 2014;73:376-84

9 Peterfy C. Imaging techniques. In: Klippel J, Dieppe P, eds. Rheumatology. 2nd edn. Philadelphia: Mosby, 1998: 1. 1-14.

10 Kellgren JH, Lawrence JS. Radiological assessment of osteoarthrosis. Ann Rheum Dis 1957;16:494-502.

11 Schiphof D, Boers M, Bierma-Zeinstra SMA. Differences in descriptions of Kellgren and Lawrence grades of knee osteoarthritis. Ann Rheum Dis 2008;67:1034-6.

12 Peterfy CG, Guermazi A, Zaim S, et al. Whole-Organ magnetic resonance imaging score (worms) of the knee in osteoarthritis. Osteoarthritis Cartilage 2004;12:177-90.

13 Smith TO, Hawker GA, Hunter DJ, et al. The OMERACT-OARSI core domain set for measurement in clinical trials of hip and/or knee osteoarthritis. J Rheumatol 2019;46:981-9.

14 Altman R, Asch E, Bloch D, et al. The American College of rheumatology criteria for the classification and reporting of osteoarthritis of the knee. Arthritis Rheum 1986;29:1039-49.

15 Downs SH, Black N. The feasibility of creating a checklist for the assessment of the methodological quality both of randomised and non-randomised studies of health care interventions. Journal of Epidemiology \& Community Health 1998:52:377-84.

16 Deeks JJ, Higgins JPT, Altman DG, Cochrane Statistical Methods Group. Chapter 9: Analysing data and undertaking meta-analyses. In: Higgins JPT, Green S, eds. Cochrane Handbook for systematic reviews of interventions. version 5.1.0. The Cochrane Collaboration, 2008. http://handbook-5-1.cochrane.org/

17 Valdes AM, Doherty SA, Zhang W, et al. Inverse relationship between preoperative radiographic severity and postoperative pain in patients with osteoarthritis who have undergone total joint arthroplasty. Semin Arthritis Rheum 2012;41:568-75.

18 Kinds MB, Marijnissen ACA, Vincken KL, et al. Evaluation of separate quantitative radiographic features adds to the prediction of incident radiographic osteoarthritis in individuals with recent onset of knee pain: 5-year follow-up in the check cohort. 2012: 20, 548-56.

19 Davis J, Eaton CB, Lo GH, et al. Knee symptoms among adults at risk for accelerated knee osteoarthritis: data from the osteoarthritis initiative. Clin Rheumatol 2017;36:1083-9.

20 Akelman MR, Fadale PD, Hulstyn MJ, et al. Effect of matching or Overconstraining knee laxity during anterior cruciate ligament reconstruction on knee osteoarthritis and clinical outcomes: a randomized controlled trial with 84-Month follow-up. Am J Sports Med 2016;44:1660-70.

21 Yu SP, Williams M, Eyles JP, et al. Effectiveness of knee bracing in osteoarthritis: pragmatic trial in a multidisciplinary clinic. Int $J$ Rheum Dis 2016;19:279-86.

22 Urish KL, Keffalas MG, Durkin JR, et al. T2 texture index of cartilage can predict early symptomatic oa progression: data from the osteoarthritis initiative. Osteoarthritis Cartilage 2013;21:1550-7.

23 Rozendaal RM, Koes BW, van Osch GJVM, et al. Effect of glucosamine sulfate on hip osteoarthritis: a randomized trial. Ann Intern Med 2008;148:268-77.

24 Roman-Blas JA, Castañeda S, Sánchez-Pernaute O, et al. Combined treatment with chondroitin sulfate and glucosamine sulfate shows no superiority over placebo for reduction of joint pain and functional impairment in patients with knee osteoarthritis: a six-month multicenter, randomized, double-blind, placebo-controlled clinical trial. Arthritis Rheumatol 2017;69:77-85.

25 Riddle DL, Jiranek WA. Knee osteoarthritis radiographic progression and associations with pain and function prior to knee arthroplasty: a multicenter comparative cohort study. Osteoarthritis Cartilage 2015;23:391-6.

26 Reginster JY, Deroisy R, Rovati LC, et al. Long-Term effects of glucosamine sulphate on osteoarthritis progression: a randomised, placebo-controlled clinical trial. Lancet 2001;357:251-6.

27 Raynauld J-P, Martel-Pelletier J, Haraoui B, et al. Risk factors predictive of joint replacement in a 2-year multicentre clinical trial in knee osteoarthritis using MRI: results from over 6 years of observation. Ann Rheum Dis 2011;70:1382-8.

28 Podsiadlo P, Cicuttini FM, Wolski M, et al. Trabecular bone texture detected by plain radiography is associated with an increased risk of knee replacement in patients with osteoarthritis: a 6 year prospective follow up study. Osteoarthritis Cartilage 2014;22:71-5.

29 Pham T, Le Henanff A, Ravaud P, et al. Evaluation of the symptomatic and structural efficacy of a new hyaluronic acid compound, NRD101, in comparison with diacerein and placebo in a 1 year randomised controlled study in symptomatic knee osteoarthritis. Ann Rheum Dis 2004;63:1611-7.

30 Pavelká K, Gatterová J, Gollerova V, et al. A 5-year randomized controlled, double-blind study of glycosaminoglycan polysulphuric acid complex (Rumalon) as a structure modifying therapy in osteoarthritis of the hip and knee. Osteoarthritis Cartilage 2000;8:335-42.

31 Michel BA, Stucki G, Frey D, et al. Chondroitins 4 and 6 sulfate in osteoarthritis of the knee: a randomized, controlled trial. Arthritis Rheum 2005;52:779-86.

32 Messier SP, Loeser RF, Miller GD, et al. Exercise and dietary weight loss in overweight and obese older adults with knee osteoarthritis: the arthritis, diet, and activity promotion trial. Arthritis Rheum 2004;50:1501-10.

33 McAlindon T, LaValley M, Schneider E, et al. Effect of vitamin D supplementation on progression of knee pain and cartilage volume loss in patients with symptomatic osteoarthritis: a randomized controlled trial. JAMA 2013;309:155-62.

34 Marsh JD, Birmingham TB, Giffin JR, et al. Cost-Effectiveness analysis of arthroscopic surgery compared with non-operative management for osteoarthritis of the knee. BMJ Open 2016;6:e009949:2015-9949.

35 Lohmander LS, Hellot S, Dreher D, et al. Intraarticular sprifermin (recombinant human fibroblast growth factor 18) in knee osteoarthritis: a randomized, double-blind, placebo-controlled trial. Arthritis Rheumatol 2014;66:1820-31.

36 Kongtharvonskul J, Woratanarat P, McEvoy M, et al. Efficacy of glucosamine plus diacerein versus monotherapy of glucosamine: a double-blind, parallel randomized clinical trial. Arthritis Res Ther 2016;18:016-1124-9..

37 Katz JN, Brophy RH, Chaisson CE, et al. Surgery versus physical therapy for a meniscal tear and osteoarthritis. $N$ Engl J Med 2013;368:1675-84.

38 Karsdal MA, Byrjalsen I, Alexandersen P, et al. Treatment of symptomatic knee osteoarthritis with oral salmon calcitonin: results from two phase 3 trials. Osteoarthritis Cartilage 2015;23:532-43. 
39 Housman L, Arden N, Schnitzer TJ, et al. Intra-Articular hylastan versus steroid for knee osteoarthritis. Knee Surg Sports Traumatol Arthrosc 2014;22:1684-92.

40 Henriksen M, Hunter DJ, Dam EB, et al. Is increased joint loading detrimental to obese patients with knee osteoarthritis? a secondary data analysis from a randomized trial. Osteoarthritis Cartilage 2013;21:1865-75.

41 Guermazi A, Hayashi D, Roemer FW, et al. Cyst-like lesions of the knee joint and their relation to incident knee pain and development of radiographic osteoarthritis: the most study. Osteoarthritis Cartilage 2010;18:1386-92.

42 Glass NA, Torner JC, Frey Law LA, et al. The relationship between quadriceps muscle weakness and worsening of knee pain in the most cohort: a 5-year longitudinal study. Osteoarthritis Cartilage 2013:21:1154-9.

43 Filardo G, Di Matteo B, Di Martino A, et al. Platelet-Rich plasma intra-articular knee injections show no superiority versus Viscosupplementation: a randomized controlled trial. Am J Sports Med 2015;43:1575-82.

44 Ettinger WH, Burns R, Messier SP, et al. A randomized trial comparing aerobic exercise and resistance exercise with a health education program in older adults with knee osteoarthritis. The fitness arthritis and seniors trial (fast). JAMA 1997;277:25-31.

45 Eckstein F, Hitzl W, Duryea J, et al. Baseline and longitudinal change in isometric muscle strength prior to radiographic progression in osteoarthritic and pre-osteoarthritic knees--data from the Osteoarthritis Initiative. Osteoarthritis Cartilage 2013;21:682-90.

46 Dougados M, Nguyen M, Berdah L, et al. Evaluation of the structure-modifying effects of diacerein in hip osteoarthritis: ECHODIAH, a three-year, placebo-controlled trial. evaluation of the Chondromodulating effect of diacerein in oa of the hip. Arthritis Rheum 2001;44:2539-47.

47 Chandrasekaran S, Gui C, Darwish N, et al. Outcomes of hip arthroscopic surgery in patients with Tönnis grade 1 osteoarthritis with a minimum 2-year follow-up: evaluation using a matched-pair analysis with a control group with Tönnis grade 0. Am J Sports Med 2016;44:1781-8.

48 Chandrasekaran S, Darwish N, Gui C, et al. Outcomes of hip arthroscopy in patients with Tönnis Grade-2 osteoarthritis at a mean 2-year follow-up: evaluation using a matched-pair analysis with Tönnis Grade-0 and Grade-1 cohorts. J Bone Joint Surg Am 2016;98:973-82.

49 Campbell DG, Duncan WW, Ashworth M, et al. Patellar resurfacing in total knee replacement: a ten-year randomised prospective trial. $J$ Bone Joint Surg Br 2006;88:734-9.

50 Brown MT, Murphy FT, Radin DM, et al. Tanezumab reduces osteoarthritic hip pain: results of a randomized, double-blind, placebo-controlled phase III trial. Arthritis Rheum 2013;65:1795-803.

51 Brown MT, Murphy FT, Radin DM, et al. Tanezumab reduces osteoarthritic knee pain: results of a randomized, double-blind, placebo-controlled phase III trial. J Pain 2012;13:790-8.

52 Bisicchia S, Bernardi G, Tudisco C. HYADD 4 versus methylprednisolone acetate in symptomatic knee osteoarthritis: a single-centre single blind prospective randomised controlled clinical study with 1-year follow-up. Clin Exp Rheumatol 2016;34:857-63.

53 Bingham CO, Buckland-Wright JC, Garnero P, et al. Risedronate decreases biochemical markers of cartilage degradation but does not decrease symptoms or slow radiographic progression in patients with medial compartment osteoarthritis of the knee: results of the two-year multinational knee osteoarthritis structural arthritis study. Arthritis Rheum 2006;54:3494-507.

54 Ahedi $\mathrm{H}$, Aitken D, Blizzard L, et al. A population-based study of the association between hip bone marrow lesions, high cartilage signal, and hip and knee pain. Clin Rheumatol 2014;33:369-76.

55 Amin S, Guermazi A, Lavalley MP, et al. Complete anterior cruciate ligament tear and the risk for cartilage loss and progression of symptoms in men and women with knee osteoarthritis. Osteoarthritis Cartilage 2008;16:897-902.

56 Antony B, Driban JB, Price LL, et al. The relationship between meniscal pathology and osteoarthritis depends on the type of meniscal damage visible on magnetic resonance images: data from the osteoarthritis initiative. Osteoarthritis Cartilage 2017;25:76-84.

57 Arden NK, Cro S, Sheard S, et al. The effect of vitamin D supplementation on knee osteoarthritis, the video study: a randomised controlled trial. Osteoarthritis Cartilage 2016;24:1858-66.

58 Ayral X, Mackillop N, Genant HK, et al. Arthroscopic evaluation of potential structure-modifying drug in osteoarthritis of the knee. A multicenter, randomized, double-blind comparison of tenidap sodium vs piroxicam. Osteoarthritis Cartilage 2003;11:198-207.

59 Baselga García-Escudero J, Miguel Hernández Trillos P. Treatment of osteoarthritis of the knee with a combination of autologous conditioned serum and physiotherapy: a two-year observational study. PLoS One 2015;10:e0145551.

60 Bevers K, Vriezekolk JE, Bijlsma JWJ, et al. Ultrasonographic predictors for clinical and radiological progression in knee osteoarthritis after 2 years of follow-up. Rheumatology 2015;54:2000-3

61 Birmingham TB, Giffin JR, Chesworth BM, et al. Medial opening wedge high tibial osteotomy: a prospective cohort study of gait, radiographic, and patient-reported outcomes. Arthritis Rheum 2009;61:648-57.

62 Brandt KD, Mazzuca SA, Katz BP, et al. Effects of doxycycline on progression of osteoarthritis: results of a randomized, placebocontrolled, double-blind trial. Arthritis Rheum 2005;52:2015-25

63 Bruyere O, Pavelka K, Rovati LC, et al. Glucosamine sulfate reduces osteoarthritis progression in postmenopausal women with knee osteoarthritis: evidence from two 3-year studies. Menopause 2004;11:138-43.

64 Conrozier T, Eymard F, Afif N, et al. Safety and efficacy of intraarticular injections of a combination of hyaluronic acid and mannitol (HAnOX-M) in patients with symptomatic knee osteoarthritis: results of a double-blind, controlled, multicenter, randomized trial. Knee 2016;23:842-8

65 Dowsey MM, Nikpour M, Dieppe P, et al. Associations between pre-operative radiographic changes and outcomes after total knee joint replacement for osteoarthritis. Osteoarthritis Cartilage 2012;20:1095-102.

66 Felson DT, Niu J, Yang T, et al. Physical activity, alignment and knee osteoarthritis: data from most and the OAl. Osteoarthritis Cartilage 2013;21:789-95

67 Felson DT, Niu J, Guermazi A, et al. Correlation of the development of knee pain with enlarging bone marrow lesions on magnetic resonance imaging. Arthritis Rheum 2007;56:2986-92.

68 Hamilton TW, Pandit HG, Maurer DG, et al. Anterior knee pain and evidence of osteoarthritis of the patellofemoral joint should not be considered contraindications to mobile-bearing unicompartmental knee arthroplasty: a 15-year follow-up. Bone Joint J 2017;99B:632-9.

69 Hellio le Graverand M-P, Clemmer RS, Redifer P, et al. A 2-year randomised, double-blind, placebo-controlled, multicentre study of oral selective iNOS inhibitor, cindunistat (SD-6010), in patients with symptomatic osteoarthritis of the knee. Ann Rheum Dis 2013;72:187-95.

70 Hochberg MC, Martel-Pelletier J, Monfort J, et al. Combined chondroitin sulfate and glucosamine for painful knee osteoarthritis: a multicentre, randomised, double-blind, non-inferiority trial versus celecoxib. Ann Rheum Dis 2016;75:37-44.

71 Hoeksma HL, Dekker J, Ronday HK, et al. Comparison of manual therapy and exercise therapy in osteoarthritis of the hip: a randomized clinical trial. Arthritis Rheum 2004:51:722-9.

72 Huang $\mathrm{M}-\mathrm{H}$, Lin $\mathrm{Y}-\mathrm{S}$, Yang R-C, et al. A comparison of various therapeutic exercises on the functional status of patients with knee osteoarthritis. Semin Arthritis Rheum 2003;32:398-406.

73 Huizinga MR, Gorter J, Demmer A, et al. Progression of medial compartmental osteoarthritis 2-8 years after lateral closingwedge high tibial osteotomy. Knee Surgery, Sports Traumatology, Arthroscopy 2017;25:3679-86.

74 Kahn TL, Soheili A, Schwarzkopf R. Outcomes of total knee arthroplasty in relation to preoperative patient-reported and radiographic measures: data from the osteoarthritis initiative. Geriatr Orthop Surg Rehabil 2013;4:117-26.

75 Kim Y-H, Park J-W, Kim J-S. The clinical outcome of ComputerNavigated compared with conventional knee arthroplasty in the same patients: a prospective, randomized, double-blind, long-term study. $J$ Bone Joint Surg Am 2017;99:989-96.

76 Lequesne M, Maheu E, Cadet C, et al. Structural effect of avocado/ soybean unsaponifiables on joint space loss in osteoarthritis of the hip. Arthritis Rheum 2002;47:50-8.

77 Messier SP, Gutekunst DJ, Davis C, et al. Weight loss reduces knee-joint loads in overweight and obese older adults with knee osteoarthritis. Arthritis Rheum 2005;52:2026-32.

78 Messier SP, Mihalko SL, Legault C, et al. Effects of intensive diet and exercise on knee joint loads, inflammation, and clinical outcomes among overweight and obese adults with knee osteoarthritis: the idea randomized clinical trial. JAMA 2013;310:1263-73.

79 Muraki S, Akune T, Nagata K, et al. Association of knee osteoarthritis with onset and resolution of pain and physical functional disability: the road study. Mod Rheumatol 2014:24:966-73.

80 Muraki S, Akune T, Nagata K, et al. Does osteophytosis at the knee predict health-related quality of life decline? a 3-year follow-up of the road study. Clin Rheumatol 2015;34:1589-97. 
81 Pavelká K, Gatterová J, Olejarová M, et al. Glucosamine sulfate use and delay of progression of knee osteoarthritis: a 3-year, randomized, placebo-controlled, double-blind study. Arch Intern Med 2002;162:2113-23.

82 Rat A-C, Baumann C, Guillemin F. National, multicentre, prospective study of quality of life in patients with osteoarthritis of the knee treated with hylane G-F 20. Clin Rheumatol 2011;30:1285-93.

83 Reginster J-Y, Badurski J, Bellamy N, et al. Efficacy and safety of strontium ranelate in the treatment of knee osteoarthritis: results of a double-blind, randomised placebo-controlled trial. Ann Rheum Dis 2013;72:179-86.

84 Romagnoli S, Marullo M, Clinical M-T. Mid-Term clinical, functional, and radiographic outcomes of 105 gender-specific Patellofemoral arthroplasties, with or without the association of medial Unicompartmental knee arthroplasty. J Arthroplasty 2018;33:688-95.

85 Sanchez-Ramirez D, Leeden M, Esch M, et al. Increased knee muscle strength is associated with decreased activity limitations in established knee osteoarthritis: two-year follow-up study in the Amsterdam osteoarthritis cohort. J Rehabil Med 2015;47:647-54.

86 Sawitzke AD, Shi H, Finco MF, et al. Clinical efficacy and safety of glucosamine, chondroitin sulphate, their combination, celecoxib or placebo taken to treat osteoarthritis of the knee: 2-year results from gait. Ann Rheum Dis 2010;69:1459-64.

87 Skou ST, Wise BL, Lewis CE, et al. Muscle strength, physical performance and physical activity as predictors of future knee replacement: a prospective cohort study. Osteoarthritis Cartilage 2016;24:1350-6.

88 Sowers M, Karvonen-Gutierrez CA, Jacobson JA, et al. Associations of anatomical measures from MRI with radiographically defined knee osteoarthritis score, pain, and physical functioning. J Bone Joint Surg Am 2011:93:241-51.

89 Spector TD, Conaghan PG, Buckland-Wright JC, et al. Effect of risedronate on joint structure and symptoms of knee osteoarthritis: results of the BRISK randomized, controlled trial [ISRCTN01928173]. Arthritis Res Ther 2005;7:R625-33.
90 Sun S-F, Hsu C-W, Lin H-S, et al. Comparison of single intraarticular injection of novel hyaluronan (HYA-JOINT plus) with Synvisc-One for knee osteoarthritis: a randomized, controlled, double-blind trial of efficacy and safety. J Bone Joint Surg Am 2017;99:462-71.

91 Weng M-C, Lee C-L, Chen C-H, et al. Effects of different stretching techniques on the outcomes of isokinetic exercise in patients with knee osteoarthritis. Kaohsiung J Med Sci 2009;25:306-15.

92 White DK, Neogi T, Nguyen U-SDT, et al. Trajectories of functional decline in knee osteoarthritis: the osteoarthritis initiative. Rheumatology 2016;55:801-8

93 Witt C, Brinkhaus B, Jena S, et al. Acupuncture in patients with osteoarthritis of the knee: a randomised trial. Lancet 2005;366:136-43.

94 Yusuf E, Bijsterbosch J, Slagboom PE, et al. Association between several clinical and radiological determinants with long-term clinical progression and good prognosis of lower limb osteoarthritis. PLoS One 2011;6:e25426.

95 Silverwood V, Blagojevic-Bucknall M, Jinks C, et al. Current evidence on risk factors for knee osteoarthritis in older adults: a systematic review and meta-analysis. Osteoarthritis Cartilage 2015;23:507-15.

96 Kingsbury SR, Corp N, Watt FE, et al. Harmonising data collection from osteoarthritis studies to enable stratification: recommendations on core data collection from an arthritis research UK clinical studies group. Rheumatology 2016;55:1394-402.

97 Nelson AE, Fang F, Arbeeva L, et al. A machine learning approach to knee osteoarthritis phenotyping: data from the FNIH biomarkers Consortium. Osteoarthritis Cartilage 2019;27:994-1001.

98 van der Esch M, van der Leeden M, Roorda LD, et al. Predictors of self-reported knee instability among patients with knee osteoarthritis: results of the Amsterdam osteoarthritis cohort. Clin Rheumatol 2016;35:3007-13.

99 Hunter DJ, Guermazi A, Lo GH, et al. Evolution of semi-quantitative whole joint assessment of knee oa: MOAKS (MRI osteoarthritis knee score). Osteoarthritis Cartilage 2011;19:990-1002. 